\title{
Hoe herkent u het zeldzame Phelan-McDermidsyndroom?
}

Willem Verhoeven, Elisa Houwink, Nicole de Leeuw, Jos Egger

De afgelopen decennia is de kennis over zeldzame ziekten en genetica toegenomen. Toch kent elke huisartsenpraktijk wel kinderen of volwassenen die nog niet gediagnosticeerd zijn met een zeldzame ziekte, terwijl ze daar wel baat bij kunnen hebben. Hoe vindt $u$ bijvoorbeeld patiënten met het zeldzame Phelan-McDermidsyndroom? Deze patiënten hebben meestal een normaal uiterlijk en een onbegrepen ontwikkelingsachterstand. De diagnose wordt vaak pas laat gesteld, en gedrags- en belevingsproblemen worden niet (h)erkend. In dit soort gevallen kunt $u$ een beroep doen op speciale expertisepoliklinieken van de universitaire ziekenhuizen. Deze hebben een geïndividualiseerd multidisciplinair begeleidingstraject opgezet om $\mathbf{u}$ te ondersteunen bij de diagnostiek, monitoring en behandeling.

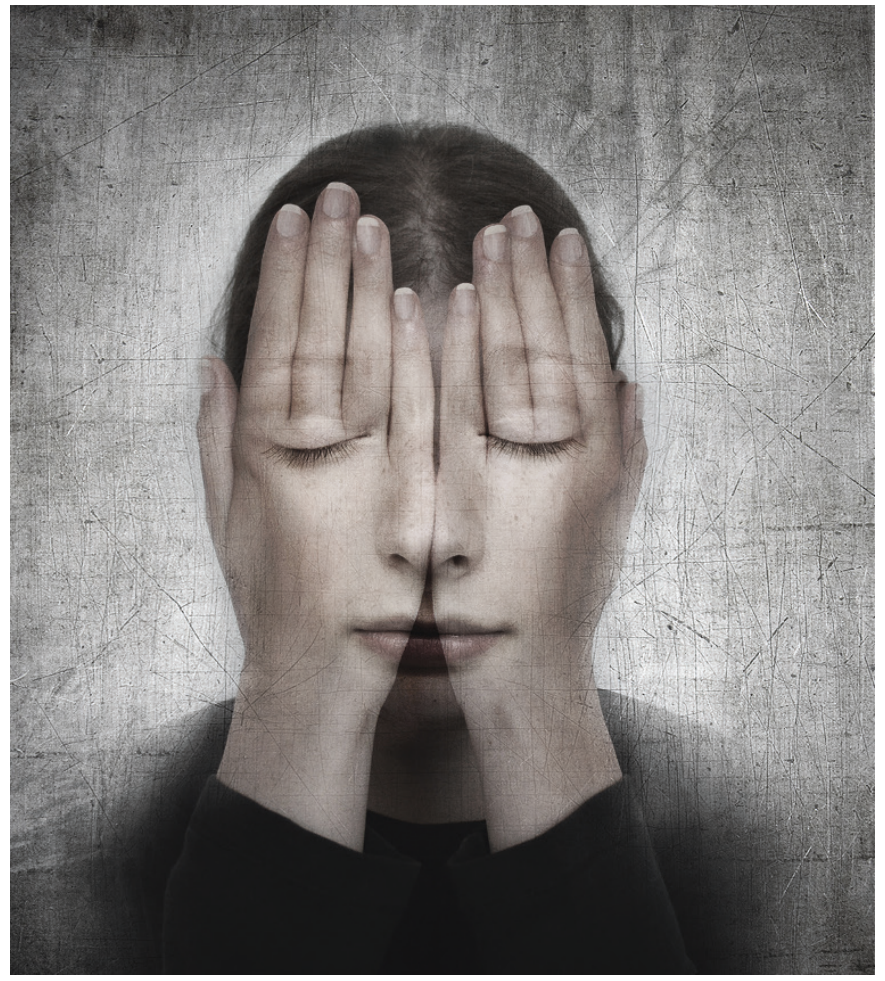

Vaak ontwikkelt zich bij patiënten met Phelan-McDermidsyndroom een psychiatrische aandoening met kenmerken die sterk doen denken aan een bipolair affectieve stoornis.

Foto: Shutterstock

\begin{abstract}
CASUS: EEN 14-JARIG MEISJE MET DIVERSE KLACHTEN
Zes jaar geleden verwijst u een 14-jarig meisje met menstruatieklachten, slaapproblemen, somberheid en moeite met het onderhouden van sociale contacten op school [ZMLK] naar de kinderarts. Ze heeft een voorgeschiedenis met slappe spieren, problemen met spraaken taalontwikkeling en een milde verstandelijke beperking. Eerdere klachten van diarree en obstipatie duidt de kinderarts als het prikkelbaredarmsyndroom. Na een uitgebreid multidisciplinair overleg en bloedonderzoek wordt er geen somatische oorzaak gevonden. Vanuit de werkdiagnose matige depressie wordt gestart met $10 \mathrm{mg}$ fluoxetine en zo nodig 2,5 mg lorazepam voor het slapen.

Op 16-jarige leeftijd verwijst $u$ haar in verband met toenemende gevoeligheid voor omgevingsprikkels opnieuw naar de kinderarts. Vanwege de autistiforme kenmerken en de eerder vastgestelde psychomotore retardatie denkt deze aan een genetische oorzaak. De kinderarts verwijst haar voor onderzoek naar de afdeling klinische genetica. Het meisje blijkt het Phelan-McDermidsyndroom te hebben. Ze wordt voor behandeladvies verwezen naar een expertisecentrum.
\end{abstract}

Het Phelan-McDermidsyndroom (PMcDS) is oorspronkelijk beschreven als een microdeletiesyndroom dat wordt veroorzaakt door een verlies van het laatste gedeelte van chromosoom 22 of een mutatie in het daar gelokaliseerde SHANK3-gen [figuur 1]. ${ }^{1,2}$ PMcDS wordt beschouwd als een zeldzame aandoening. De incidentie van PMcDS in Nederland is ruwweg geschat 1:30.000 pasgeborenen. Dit is een onderschatting, omdat de diagnose meestal pas op latere leeftijd wordt gesteld. ${ }^{3,4}$ De meest voorkomende kenmerken van PMcDS zijn neonatale hypotonie, bovensteluchtweginfecties, verstandelijke beperkingen, een fors vertraagde of afwezige taal en spraak, een sterk verhoogde gevoeligheid voor omgevingsprikkels en symptomen binnen het autismespectrum. Ook komen congenitale afwijkingen aan hart en nieren voor, naast hypothyreoidie, een verminderd vermogen tot transpireren, lymfoedeem, een verhoogde pijndrempel en epilepsie. Het uiterlijk vertoont vaak geen opvallende misvormingen.

Vanaf de adolescentie ontwikkelt zich zeer vaak een psychiatrische aandoening met kenmerken die sterk doen denken aan een bipolair affectieve stoornis. Een prikkelbare stemming met opstandig gedrag wordt afgewisseld met somberheid en terugtrekken, al dan niet uitgelokt door acute infecties, hormonale veranderingen of stressvolle omgevingsfactoren, zoals overvraging. 


\section{DE KERN}

- Hoewel zeldzame ziekten weinig voorkomen, zijn patiënten met zeldzame ziekten talrijk, ook in de huisartsenpraktijk.

- Bij diverse syndromen zijn dikwijls minder of zelfs helemaal geen dismorfe kenmerken zichtbaar. Bij deze personen ligt, ongeacht hun leeftijd, het grote gevaar van overvraging op de loer.

- Behalve via diverse multidisciplinaire expertisecentra van de universitaire ziekenhuizen zijn ook specialistische consultatie en advies mogelijk via 2 op dit gebied actieve TOPGGz-afdelingen.

- Het Phelan-McDermidsyndroom is een voorbeeld van een zeldzame ziekte zonder dismorfe kenmerken, maar met een fenotype met vaak een stoornis binnen het bipolaire spectrum.

\section{Figuur 1}

Chromosoom 22

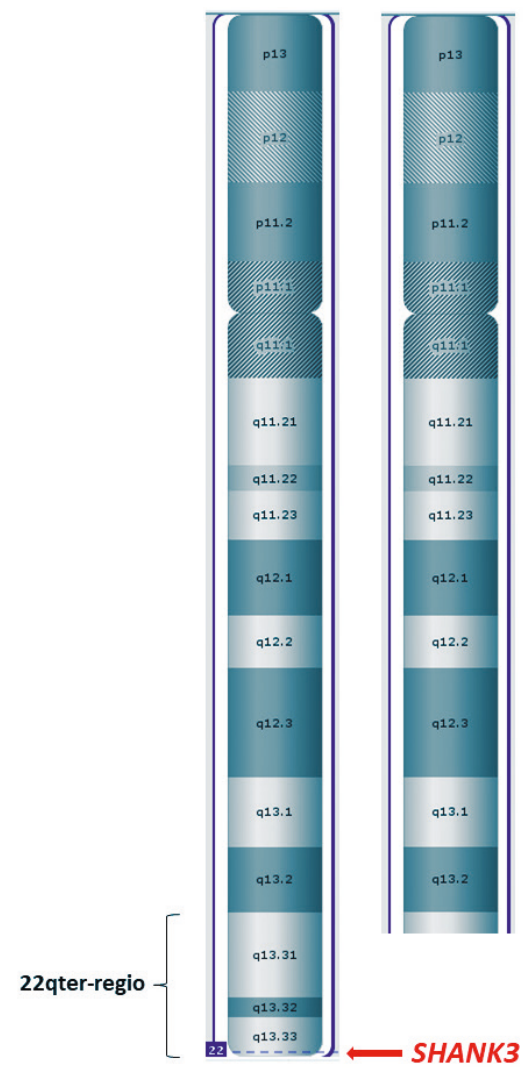

\section{BESCHOUWING}

Het is niet eenvoudig om in de huisartsenpraktijk een zeldzame aandoening als PMcDS op te sporen. Sommige patiënten met zeldzame ziekten vertonen aspecifieke klachten, zoals spierslapte, een lichte groeiachterstand, een vertraagde ontwikkeling of slaapstoornissen. Dergelijke syndromen zijn ook

\section{CASUS: 14-JARIG MEISJE [VERVOLG]}

$\mathrm{Na}$ advies vanuit het expertisecentrum over aanvullend somatisch onderzoek om overige gerelateerde congenitale afwijkingen uit te sluiten, stopt ze met fluoxetine. Ze wordt ingesteld op valproïnezuur. Onder leiding van een gedragsdeskundige worden de dagactiviteiten beter op haar mogelijkheden afgestemd. Hiermee blijft haar stemming tot haar 18e jaar stabiel. Tijdens de COVID-19-pandemie ontstaat een hypomane periode met overactiviteit, overdreven vrolijkheid en slaapstoornissen. Onder begeleiding van een psycholoog en met toevoeging van quetiapine en een lage dosering lorazepam, functioneert de inmiddels २० jaar oude patiënte weer op haar oude niveau.

voor kinderartsen relatief onbekend of in het verleden aan hun aandacht ontsnapt.

Onder de term 'zeldzame ziekten' verstaan we ziekten die voorkomen bij een relatief klein aantal mensen en die door hun zeldzaamheid specifieke problemen met zich meebrengen. Volgens de door de Europese Commissie van Experts op het gebied van Zeldzame Ziekten uitgevaardigde richtlijnen wordt in Europa een ziekte geclassificeerd als zeldzaam wanneer deze bij minder dan 1 op de 2000 mensen voorkomt. In Nederland lijden ongeveer 1 miljoen mensen aan een zeldzame ziekte, wat neerkomt op circa 100 tot 150 patiënten per gemiddelde huisartsenpraktijk. ${ }^{5}$ Zeldzame ziekten zijn dus niet echt zeldzaam in de huisartsenpraktijk.

[Figuur 2] laat zien wanneer $u$ aan een zeldzaam syndroom moet denken.

Via een uitgebreide (hetero)anamnese waarin $u$ deze aandachtspunten systematisch naloopt, krijgt $\mathrm{u}$ beter zicht op deze vaker in samenhang voorkomende verschijnselen. Zo kunt $\mathrm{u}$ op het spoor komen van een onderliggend syndroom (zonder al precies te weten welk) en aanwijzingen vinden voor verwijzing voor klinisch genetisch onderzoek. ${ }^{6,7} \mathrm{U}$ kunt zo'n verwijzing zelfstandig vormgeven en richten aan de kinderarts, kinderneuroloog of klinisch geneticus.

Wanneer $u$ vermoedt dat er sprake is van een mogelijke genetische oorzaak, kunt u zich voor advies sinds enige tijd ook wenden tot een multidisciplinair expertisecentrum (huisartsengenetica.nl/verwijzen). Omdat u niet dagelijks met zeldzame aandoeningen in aanraking zult komen, is het goed te weten dat er speciale expertisepoliklinieken zijn ingericht bij de universitaire ziekenhuizen (zichtopzeldzaam.nl) en bij een tweetal landelijk werkende ggz-instellingen met TOPGGz-erkenning op dit gebied (Vincent van Gogh en Lentis). Deze verzorgen de begeleiding en ondersteuning bij de behandeling van patiënten met een zeldzaam syndroom, waarvoor meestal de gelijktijdige inzet van deskundigheid uit meerdere disciplines vereist is.

\section{LITERATUUR}

1. Phelan MC. Deletion 22q13.3 syndrome. Orphanet J Rare Dis 2008;3:14.

2. De Rubeis S, Siper PM, Durkin A, Weissman J, Muratet F, Halpern $\mathrm{D}$, et al. Delineation of the genetic and clinical spectrum of Phelan-McDermid syndrome caused by SHANK3 point mutations. Mol Autism 2018;9:31. 


\section{Figuur 2}

Problemen die op een zeldzaam syndroom kunnen wijzen

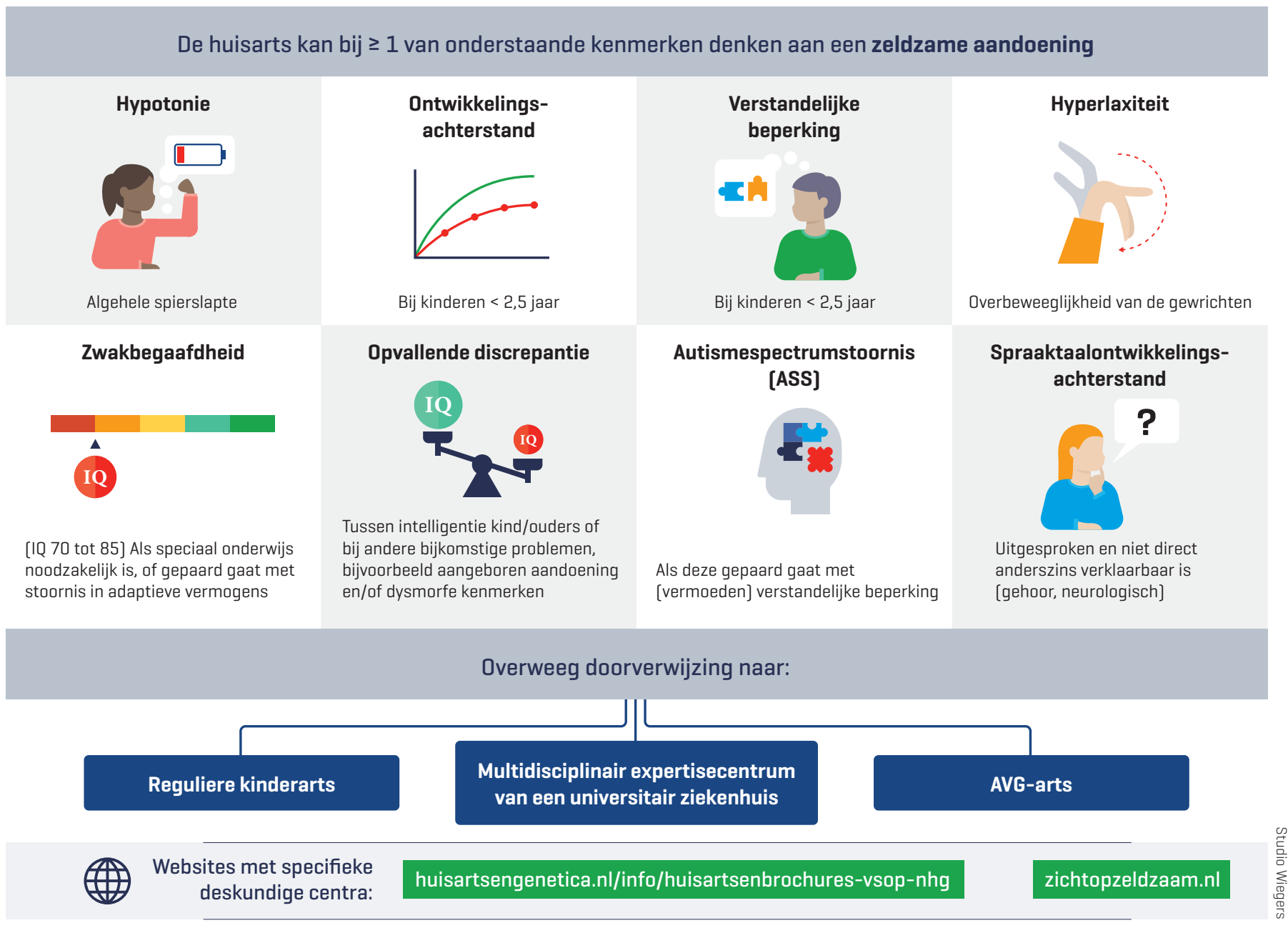

3. Gomez-Taylor B, Moreno Sancho ML, Drehmer Rieger E, Carrera Juliá S, Nevado J, Sempere Ferre F. Prevalence of the Phelan-McDermid Syndrome in Spain. Rev Esp Salud Pública 2020;94:21.

4. Unique. Phelan McDermid syndroom: 22q13 deleties. 2020. Beschikbaar via: https://www.rarechromo.org/guide/22q13-deletions-dutch/. Geraadpleegd op 5 november 2020.

5. Orphanet. Over zeldzame ziekten. 2019. Beschikbaar via: http:// www.orphanet.nl/national/NL-NL/index/over-zeldzame-ziekten/. Geraadpleegd op 6 augustus 2021.

6. Willemsen $\mathrm{MH}$, Kleefstra T. Genetische diagnostiek bij verstandelijke beperkingen. Wat levert het op? NTvG 2014;158:A8098.

7. Houwink EJF. Huisarts en genetica en zeldzame ziekten. Bijblijven 2016;32:513-25.
Verhoeven WMA, Houwink EJF, De Leeuw N, Egger JIM. Hoe herkent $u$ het zeldzame Phelan-McDermidsyndroom? Huisarts Wet 2021;64[11]:68-70. D0l:10.1007/s12445-021-1292-y. Erasmus MC, afdeling Psychiatrie, Rotterdam: prof. dr. W.M.A. Verhoeven, emeritus hoogleraar psychofarmacotherapie. Leids Universitair Medisch Centrum, Public Health en Eerstelijnsgeneeskunde [PHEG], Leiden: dr. E.J.F. Houwink, universitair hoofddocent. Radboudumc, afdeling Genetica, Nijmegen: dr. N. de Leeuw, laboratoriumspecialist klinische genetica. Vincent van Gogh, Topklinisch Centrum voor Neuropsychiatrie, Venray: prof. dr. J.I.M. Egger, hoogleraar contextuele neuropsychologie.

Mogelijke belangenverstrengeling: niets aangegeven. 